\title{
Research on Welding Residual Stresses of Welded H-Beam Considering Butt Weld and Fillet Weld
}

\author{
Changchao Zhou ${ }^{1}$, Jia Liu ${ }^{2, a}$, Runchang Zhang ${ }^{1}$
}

1. School of Civil Engineering and Architecture, Wuhan University of Technology, Wuhan 430070,China ;

2. Hubei Key Laboratory of Roadway Bridge and Structure Engineering, Wuhan University of Technology, Wuhan 430070, China

a drliujia@126.com

Keywords: welding; residual stresses; welded $\mathrm{H}$-section; butt weld; fillet weld

\begin{abstract}
In this paper, welding residual stresses of welded H-beam considering both butt weld and fillet weld have been researched. Taking the welded H-beam frame as background, basing on technological parameters of arc welding, construction sequence and the fabricated method, the three dimensions thermal-mechanics finite element model of the welded H-beam has been established by the finite element analysis software. The distribution of welding residual stresses of welded H-beam considering both butt weld and fillet weld are simulated, and the simulation results are compared with the results that not considering butt weld. Numerical simulation results show that complicated stresses state appears in the junction between the butt weld and fillet weld, and the residual stress peak value increases.
\end{abstract}

\section{Introduction}

The welding plays an important role in the construction of the steel bridges. However, welding residual stress produced in the weld and its nearby area will seriously affect the fatigue life of steel bridges and have a significant security risk. Scholars in China and overseas have done many studies in aspects of numerical simulation, test and measurement on welding residual stress[1-4]. Peric established three-dimensional entity unit and shell-solid finite element thermodynamic model of $\mathrm{T}$ nodes, the welding residual stress distribution of H-beam fillet weld is investigated by both numerical simulation and experiments[5]. Heinze established three-dimensional model of thick plate butt welding and obtained distribution of thick plate multipass welding through studying thick plate multipass welding by numerical simulation and experiments[6]. Based the monolithic joint in Dongjiang Bridge, Yong-hui huang designed a 1:1 full scale model of the bridge node and tested the important parts of the node, thus obtained welding residual stress value of the important parts of the node[7]. Among all the research, welding residual stresses of welded H-beam considering both butt weld and fillet weld have not been studied pretty well. The welded $\mathrm{H}$-section first prefabricated forming by fillet weld connection in the factory, and then assemble through the butt weld connection at the scene, so it's meaningful to research welding residual stresses considering two types of welding. In the paper, welding residual stresses of welded H-beam considering both butt weld and fillet weld have been researched. The distribution of welding residual stresses are simulated, and the simulation results are compared with the results that not considering butt weld.

\section{Thermodynamics finite element model}

\subsection{Thermal equation}

Transient nonlinear heat conduction differential equations of the welding process can be expressed as [5]: 


$$
\frac{\partial}{\partial x}\left(k_{x} \frac{\partial T}{\partial x}\right)+\frac{\partial}{\partial y}\left(k_{y} \frac{\partial T}{\partial y}\right)+\frac{\partial}{\partial z}\left(k_{z} \frac{\partial T}{\partial z}\right)+Q=\rho C \frac{\partial T}{\partial t}
$$

Where $k_{x} 、 k_{y} 、 k_{z}$ are the thermal conductivity of $\mathrm{x}, \mathrm{y}, \mathrm{z}$ direction, respectively, $Q=\eta U I / V_{H}$ is the heat production, $\eta$ is the heat efficiency, $U$ and $I$ are voltage and current when welding , respectively. $V_{H}$ is volume of weld unit; $\rho$ and $C$ are the parent metal density and specific heat, respectively; $T$ is the temperature produced by welding; $t$ is the time.

\subsection{Finite element model}

In this paper, welding process of nodes on steel bridge was simulated by ANSYS. Finite element model is set up on the basis of the construction drawings of the large-span steel frame bridge ( Fig.1 ). H-beam is made of Q235 steel and its section height is $800 \mathrm{~mm}$. Its flange width and thickness is $400 \mathrm{~mm} 、 35 \mathrm{~mm}$, respectively. Web thickness of H-beam is $35 \mathrm{~mm}$. Butt weld of $\mathrm{H}$ beam has equal thickness. The three dimensions thermal-mechanics finite element model ( Fig.2) has been established by finite element analysis software. Thermal model using Solid70 unit and mechanical model using Solid185 unit, finite element grids are denser where near the fillet weld and butt weld. Length of finite element model is $2.4 \mathrm{~m}$ and the number of hexahedron units is 18360 .

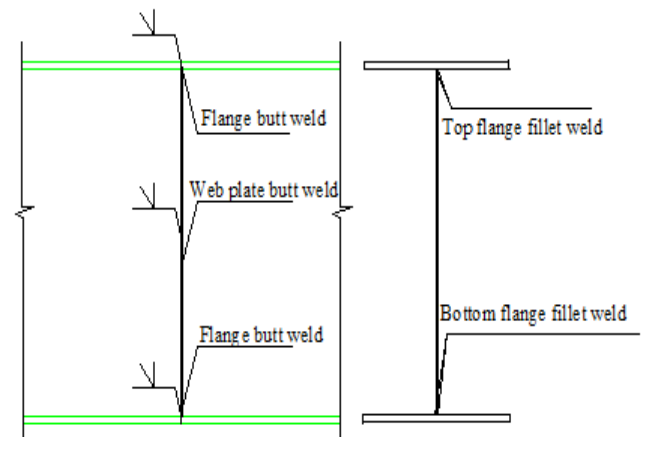

Fig.1: H-beam

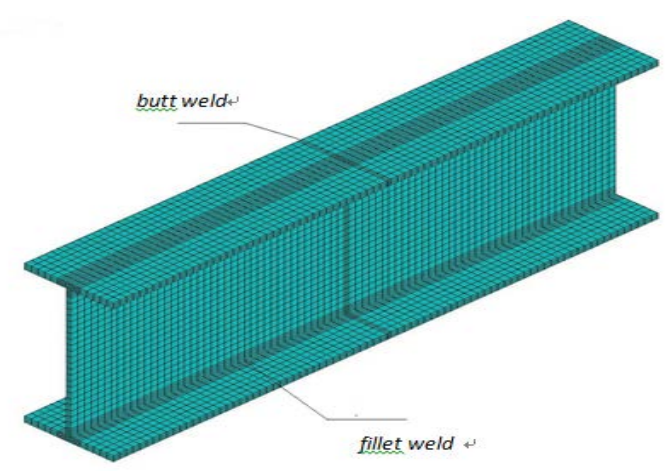

Fig.2: Finite element model of H-beam

\subsection{Heat source and welding parameters}

Selection of welding heat source shall comply with the double-ellipsoid heat source model of arc welding, welding parameters using actual electric arc welding [8] are shown in Table 1.

Table 1: Welding parameters

\begin{tabular}{lllll}
\hline $\mathrm{U}$ & $\mathrm{I}$ & $\mathrm{v}$ & $\eta$ & $\mathrm{R}$ \\
\hline $30 \mathrm{~V}$ & $350 \mathrm{~A}$ & $10 \mathrm{~mm} / \mathrm{s}$ & $70 \%$ & $0.007 \mathrm{~mm}$ \\
\hline
\end{tabular}

The welded H-section first prefabricated forming by fillet weld connection in the factory, and then assemble [9] through the butt weld connection at the scene. So the welding simulating order: first welding and cooling to fillet weld, then welding and cooling simulation to butt weld.

\section{Numerical simulation for welding residual stresses}

\subsection{Welding Residual Stress Analysis}

Numerical analysis is performed for the distribution of welding residual stresses of welded H-beam considering both fillet weld connection and butt weld. Fig.3 shows the Von-Mises equivalent welding residual stress distribution nephogram for bridge nodes. As can be seen from Fig.3, welding residual stress in fillet weld of welded H-beam is distributed along weld direction, stress distribution more uniform. Distribution of stress is relatively uniform. The maximum of Von-Mises 
equivalent welding residual stress is $153 \mathrm{Mpa}$ in fillet weld that the junction between top flange plate and web plate. But residual stress in vertical direction of the weld gradually decreases with distance far from the weld area. Fig.4 shows relation curve that represent Von-Mises equivalent welding residual stress changing along the length direction of weld in top flange plate and web plate fillet weld. From the Fig. 4 we know that the equivalent welding residual stress distribution in butt weld is complex. Due to both sides of the intersection is characterized by compressive stress, the equivalent welding residual stress on both sides mutated, when it is 0.4 meters far from the intersection, the equivalent welding residual stress restores to the greater value and changes smooth along the length direction of the weld. Its value is maintained at about $150 \mathrm{Mpa}$.

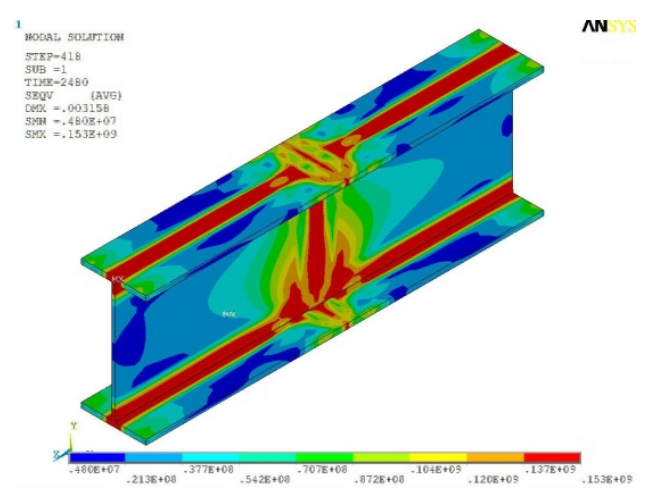

Fig.3:Von-Mises equivalent welding residual stress distribution nephogram

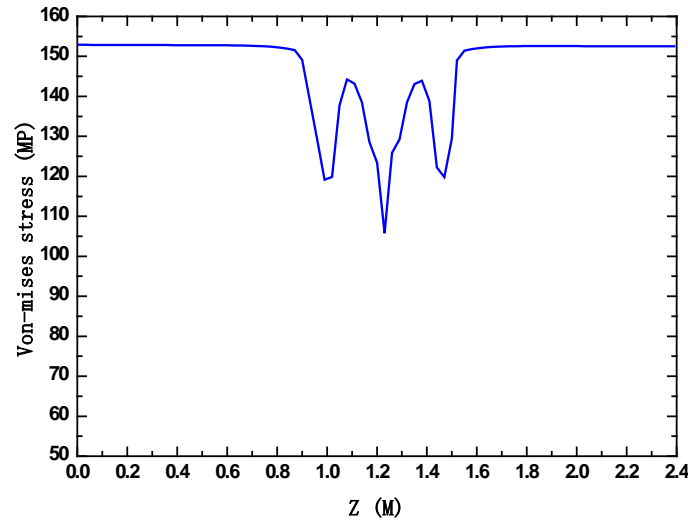

Fig.4: Von-Mises equivalent welding residual stress distribution in the top flange plate and web

Fig.5 shows longitudinal welding residual stress nephogram of welded H-beam. As can be seen from Fig.5, the longitudinal distribution of welding residual stress conforms to the Von Mises criterion. The maximum value of longitudinal welding residual stress is $171 \mathrm{Mpa}$ in fillet weld that the junction between top flange plate and web plate and characterized by tensile stress. The maximum value of compressive stress is $151 \mathrm{Mpa}$ in butt weld that is on the edge of the bottom flange. Fig. 6 shows relation curve that represent longitudinal welding residual stress changing along the length direction of weld in top flange plate and web plate fillet weld. From the curve variation we know that tensile stress in butt weld is reduced quickly and compressive stress appears. When it is away from the butt weld area, longitudinal welding residual stress keep the original larger tensile stress and its change is relatively stable.

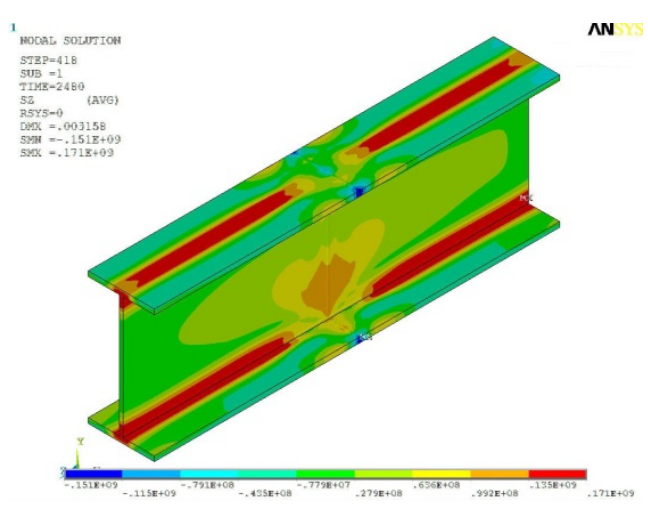

Fig.5:.Longitudinal welding residual stress nephogram

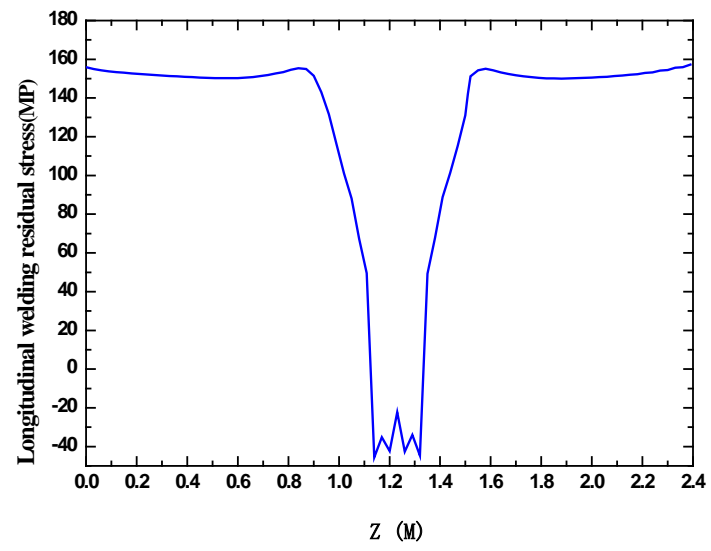

Fig.6:Longitudinal welding residual stress changing along the length direction of weld in top flange plate and web plate fillet weld

According to the foregoing, after adding the butt weld, complicated stresses state of tension compression alternating appears in the fillet weld. 


\subsection{Comparison whether the butt weld residual stress or not}

Fig.7 shows distribution curve for transverse residual stress of H-beam cross-section in butt weld. As can be seen from Fig.7, distribution of transverse residual stress presents that the top and bottom flange is characterized by compressive stress and web is characterized by tensile stress. The maximum value of compressive stress is $150.5 \mathrm{Mpa}$ in the edge of top and bottom flange. The maximum value of tensile stress is $121.2 \mathrm{Mpa}$ in web fillet weld. Fig.8 shows distribution curve for longitudinal residual stress of H-beam cross-section in butt weld. As can be seen from Fig.8, distribution curve for longitudinal residual stress is characterized by tensile stress in butt weld. In addition to smaller compressive stress exists on the top and bottom flange edges, there are significant tensile stress in the vast majority of cross section. The maximum value of tensile stress is 169.7 Mpa in web where butt weld and fillet weld intersect.

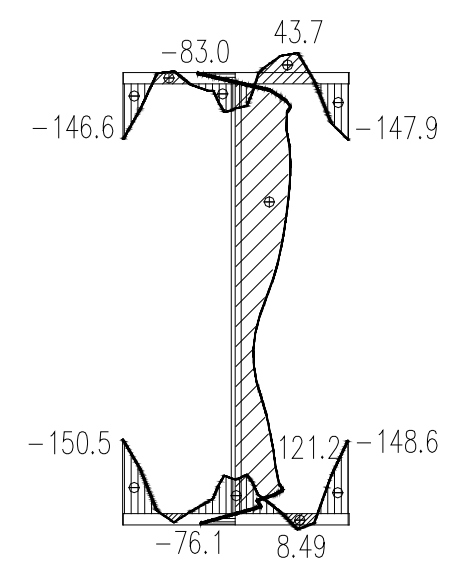

Fig.7: Distribution curve for transverse residual Stress of H-beam cross-section in butt weld

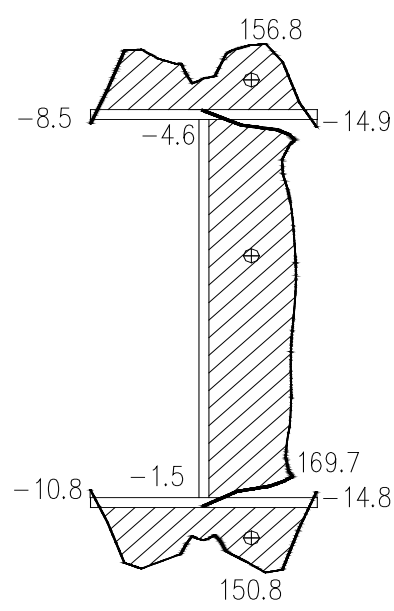

Fig.8: Distribution curve for longitudinal Residual Stress of H-beam cross-section in butt weld

Fig.9 shows distribution curve for transverse residual stress of H-beam cross-section in no butt weld. As can be seen from Fig.9, amplitude of the transverse welding residual stress is small, the maximum value is only 8.4 Mpa near the junction between flange plate and web plate. Figure10 shows distribution curve for longitudinal residual stress of H-beam cross-section in no butt weld. Distribution of Longitudinal welding residual stress is significant in the cross-section of no docking box girder. Residual stress is larger in fillet weld between flange and web. The residual stress is smaller in other parts. It is consistent with the actual stress distribution. The maximum value of tensile stress is $152.9 \mathrm{Mpa}$. Comparing distribution curves of transverse residual stress in Fig.7 and Fig.9, we can conclude that butt weld has big transverse residual compressive stress in the butt weld angle points that lead to butt weld stress distribution complex in girder corner. Comparing Fig.8 and Fig.10, we can conclude that longitudinal residual stress of H-beam cross-section is changed by butt welding. Residual stress decreases in the flange that intersects with the fillet weld, while the residual stress increases in other parts. The value of residual stress is larger on the web butt weld. The reason is that longitudinal shrinkage along the weld direction is restricted, butt weld break stress equilibrium of the fillet weld that based on longitudinal residual stress and high temperature generated by butt welding eliminates the original residual stress in the butt weld. New residual stress generates when butt weld cooling. That complicated stresses state of tension compression alternating appears in the junction between the fillet weld connection and butt weld and generated by new butt welding residual stress and the original residual stress. 


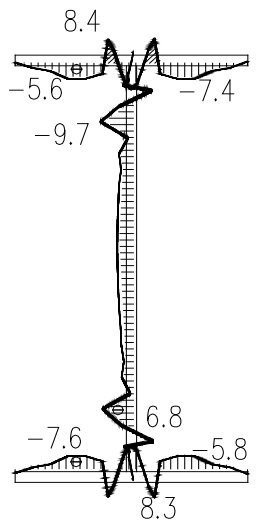

Fig.9: Transverse residual Stress of H-beam cross-section in no butt weld (Mpa)

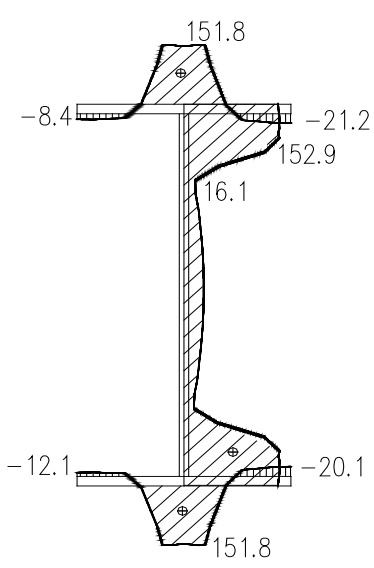

Fig.10: Longitudinal residual Stress of H-beam cross-section in no butt weld (Mpa)

\section{Conclusions}

a v Numerical analysis of welding residual stress in H-beam welds indicate that the peak value of welding residual stress in $\mathrm{H}$-beam welds is close to the material yield strength.

b v the peak value of transverse welding residual stress of H-beam cross-section in butt weld is compressive stress in flange edge. The peak value of longitudinal residual stress appears in the junction between the web butt weld connection and fillet weld.

c、 The results of numerical analysis of welding residual stress considering both fillet weld and butt weld shows that distribution area of the larger value of longitudinal welding residual stress of $\mathrm{H}$ beam cross-section significantly increase due to butt welding.

\section{Acknowledgements}

The research work was supported by the National Natural Science Foundation Program (51108363) and the Natural Science Foundation of Hubei Province of China (2014CFB849).

\section{References}

[1] Deng D. FEM prediction of welding residual stress and distortion in carbon steel considering phase transformation effects . Materials and Design, 30(2),pp .359-366,2009.

[2] Braga D, Coules HE, Pirling T. Assessment of residual stress of welded structural steel plates with or without post weld rolling using the contour method and neutron diffraction. Journal of Materials Processing Technology, 213 (12), pp. 2323-2328, 2013.

[3] D.J.Yan, X.S. Liu, J.G. Yang. Effect of thermo physical parameters on the hump feature of welding residual stress by finite element analysis. Transactions of the China,31(6), pp.5660,2010. In Chinese

[4] Skal's'kyi VR, Rudavs'kyi DV. Numerical analysis of residual stresses near a weld in the course of electron-beam welding of thick plates . Materials Science, 48(3), pp.355-363,2012.

[5] Peric M, Tonkovic Z, Rodic A. Numerical analysis and experimental investigation of welding residual stresses and distortions in a T-joint fillet weld. Materials and Design, 53(1), pp.1052$1063,2014$.

[6] Heinze C. Numerical calculation of residual stress development of multi-pass gas metal arc welding. Journal of Constructional Steel Research, 72(5), pp.12-19, 2012. 
[7] Y.H.Huang, R.H.Wang. Experiment on welding residual stress of integral joint for steel truss bridge . China Journal of Highway and Transport, 24 (1), pp.83-88. 2011. In Chinese

[8] Y.C.Chen. Manual welding procedure qualification. BeiJing: China Machine Press, 2000. In Chinese

[9] S.Cheng, H.L.Wang, J.L.Han. Review of the study of integral panel points of steel truss girder. Steel Construction, 27(6), pp.1-4,2012. In Chinese 